\title{
Comparison between lignocaine nebulization and airway nerve block for awake fiberoptic bronchoscopy-guided nasotracheal intubation: a single-blind randomized prospective study
}

\author{
Pooja Rawat Mathur, Neena Jain, Aji Kumar, Beena Thada, Veena Mathur, \\ and Deepak Garg \\ Department of Anesthesia, Jawaharlal Nehru Medical College, Ajmer, India
}

\begin{abstract}
Background: The preferred management strategy for difficult airways is awake fiberoptic bronchoscopy-guided intubation, which requires effective airway anesthesia to ensure patient comfort and acceptance. This randomized single-blind prospective study was conducted to compare lignocaine nebulization and airway nerve block for airway anesthesia prior to awake fiberoptic bronchoscopy-guided intubation.

Methods: Sixty adult patients scheduled for surgical procedures under general anesthesia were randomly allocated to two groups. Group N received jet nebulization ( $10 \mathrm{ml}$ of $4 \%$ lignocaine) and Group B received bilateral superior laryngeal and transtracheal recurrent laryngeal nerve blocks (each with $2 \mathrm{ml}$ of $2 \%$ lignocaine) followed by fiberoptic bronchoscopy-guided nasotracheal intubation. All patients received procedural sedation with dexmedetomidine. The intubation time, intubating conditions, vocal cord position, cough severity, and degree of patient satisfaction were recorded. Student's $t$ test was used to analyze parametric data, while the Mann-Whitney $U$ test was applied to non-parametric data and Fisher's test to categorical data. P values $<0.05$ were considered statistically significant.

Results: The time taken for intubation was significantly shorter in Group B [115.2 (14.7) s compared with Group N [214.0 (22.2) s] ( $\mathrm{P}=0.029)$. The intubating conditions and degree of patient comfort were better in Group B compared with Group N. Although all patients were successfully intubated, patient satisfaction was higher in Group B.

Conclusions: Airway nerve blocks are preferable to lignocaine nebulization as they provide superior-quality airway anesthesia. However, nebulization may be a suitable alternative when a nerve block is not feasible.
\end{abstract}

Keywords: Airway management; Dexmedetomidine; Intubation; Lignocaine; Nebulizers; Nerve block.

Corresponding author: Pooja Rawat Mathur, M.D.

Department of Anesthesia, Jawaharlal Nehru Medical College, Ajmer, Rajasthan 305001, India

Tel: 91-1452641396, Fax: 91-145264396, Email: drpoojarawat@gmail.com

ORCID: https://orcid.org/0000-0002-6707-0527

Received: March 24, 2017. Revised: April 15, 2017. Accepted: May 15, 2017.

Korean J Anesthesiol 2018 April 71(2): 120-126

https://doi.org/10.4097/kjae.2018.71.2.120

(c) This is an open-access article distributed under the terms of the Creative Commons Attribution Non-Commercial License (http://creativecommons.org/ licenses/by-nc/4.0/), which permits unrestricted non-commercial use, distribution, and reproduction in any medium, provided the original work is properly cited. 


\section{Introduction}

An unanticipated difficult airway can jeopardize the life of the patient; administering general anesthesia can be disastrous in such situations if the airway is not secured before induction. Awake intubation using a flexible fiberoptic bronchoscope is considered a safe and relatively simple method for intubating the trachea under direct vision in most situations [1]. The various indications of awake fiberoptic intubation include cervical spine instability, facial fractures, partially obstructing laryngeal lesions (e.g., papilloma), craniofacial abnormalities, and temporomandibular joint ankylosis [2,3]. A prerequisite for awake fiberoptic intubation is appropriate anesthesia of the nose, oropharynx, larynx, and trachea, to suppress airway reflexes and prevent discomfort during bronchoscopy and intubation. A variety of techniques are currently used for airway anesthesia including topical anesthesia (with the mucosal application of local anesthetic as a spray, viscous solutions, soaked cotton pledgets, and nebulization) or as airway nerve blocks [4]. Despite the availability of these numerous methods for airway anesthesia, few studies have compared them. Airway nerve blocks are frequently used for awake fiberoptic intubation because they provide rapid and deep anesthesia. Nebulization of local anesthetics is another promising technique, in which the airway is anesthetized completely without the need for multiple painful injections. Therefore, we compared nerve block, which is considered the standard technique for achieving rapid and effective airway anesthesia, with lignocaine nebulization, which constitutes a simple, painless, and comfortable alternative for anesthetizing the airway, before awake fiberoptic bronchoscopy-guided intubation. When carried out under minimal sedation, these techniques help to allay anxiety so that the patient is more cooperative during the procedure [5]. In this study, we used dexmedetomidine infusion for procedural sedation, which results in a stable hemodynamic profile and prevents desaturation by preserving the respiratory function of the patient.

This randomized study was conducted to compare the efficacy of jet nebulization of lignocaine and airway nerve block for achieving airway anesthesia before awake fiberoptic bronchoscopy-guided intubation. The primary objective was to compare the intubation time of the two techniques, and the secondary objectives were to assess the quality of airway anesthesia, the degree of patient comfort, and post-operative patient satisfaction.

\section{Materials and Methods}

This study was conducted after receiving approval from the ethical committee of our institution. Sixty adult patients (males and females), aged from 18-60 years, with American Society of Anesthesiologists (ASA) physical status of I-II, and undergo- ing surgery under general anesthesia at our institution, were randomly selected for inclusion. Patients who did not provide consent, had an allergy to any study drug, or were asthmatic, epileptic, hemodynamically unstable, or had a deranged coagulation profile were excluded from the study (Fig. 1).

All patients underwent a pre-anesthetic evaluation that included a thorough airway examination. The procedure of awake fiberoptic bronchoscopy-guided intubation was explained to all patients and informed consent was then obtained. The patients were randomly allocated to two groups using computer-generated tables of random numbers. For the purpose of investigator blinding, patients were first taken to the anesthesia procedure room. After obtaining baseline parameters, such as heart rate, non-invasive blood pressure, oxygen saturation, and electrocardiographic data, a line was secured for intravenous infusion of ringer lactate. Glycopyrrolate $(5 \mu \mathrm{g} / \mathrm{kg})$ was administered intravenously (IV) and two drops of xylometazoline $0.1 \%$ were instilled in the nasal cavity. Midazolam $(20 \mu \mathrm{g} / \mathrm{kg}$, IV) and dexmedetomidine $(1 \mu \mathrm{g} / \mathrm{kg}$, IV) were infused over a $15-\mathrm{min}$ period to achieve procedural sedation (Ramsay sedation score of 3 ). Then, Group N patients $(\mathrm{n}=30)$ received $10 \mathrm{ml}$ of $4 \%$ lignocaine $\left(\mathrm{Lox}^{\mathrm{TM}}\right.$, topical; Neon Laboratories Ltd., India) via a pneumatic (jet) nebulizer (Model no. 23542; Dräger Medical GmbH, Germany) for 15 min. In Group B patients $(n=30), 1 \mathrm{ml}$ of $2 \%$ lignocaine jelly was applied to the nasal mucosa, followed by bilateral superior

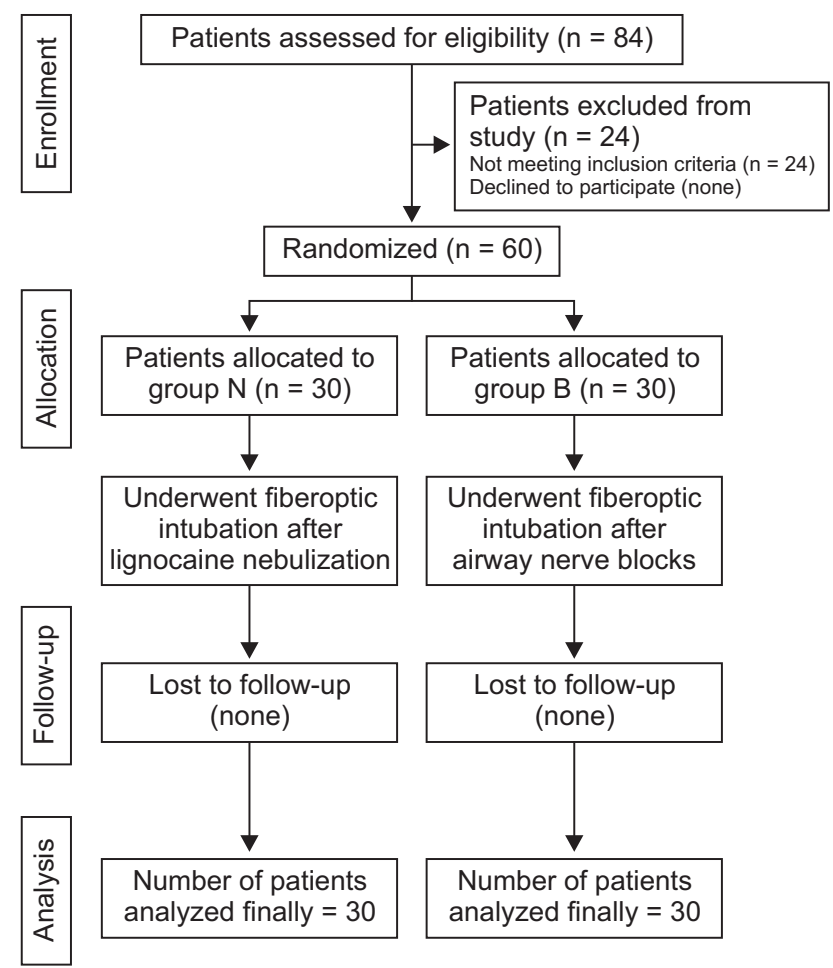

Fig. 1. CONSORT flow chart. 
laryngeal nerve block and transtracheal instillation of $2 \mathrm{ml}$ of $2 \%$ lignocaine (Lox ${ }^{\mathrm{TM}}$, injection; Neon Laboratories Ltd., India) and $10 \%$ lignocaine spray (Lox ${ }^{\mathrm{TM}}$, spray; Neon Laboratories Ltd., India) over the bilateral tonsillar area. Adequate local anesthesia was confirmed by the heaviness of the tongue in Group $\mathrm{N}$ patients, and by hoarseness of voice in Group B patients. To ensure investigator blinding, nebulization and blocks were administered by an independent anesthesiologist, and the patient was then moved from the procedure room to the operating room where, after recording the vital signs, another blinded senior anesthesiologist, with previous experience of at least 50 successful fiberoptic bronchoscopy-guided intubations, performed the procedure. A 5.0-mm flexible fiberoptic bronchoscope (Model no. 11301BN1; Karl Storz GmbH \& Co. KG, Germany) with a flexometallic endotracheal tube with an internal diameter of 7.0 or $8.0 \mathrm{~mm}$ (for males and females, respectively), was used. Parameters including intubating conditions and vocal cord position (Table 1) were recorded by the anesthesiologist performing the fiberoptic bronchoscopy-guided intubation, while intubation time, patient comfort (Table 1), and vital signs were recorded by another independent observer who was blinded to the group assignment. Vital signs were recorded after 1, 3, 5, and $10 \mathrm{~min}$ of intubation. Intubation time was defined as the time from passing the flexible fiberoptic bronchoscope tip through the nostril to the first reading obtained by the capnograph after endotracheal intubation. Scores for intubating conditions (Table 1) indexed the ease of intubation, which in addition to airway anatomy also depends on optimal airway anesthesia (in turn leading to successful suppression of pharyngeal and laryngeal reflexes, as well as the movement of the vocal cords). Patient comfort was assessed according to cough severity and comfort during and after intubation (Table 1). After confirmation of endotracheal intubation by capnography, general anesthesia was achieved with propofol (2 mg/kg, IV) and vecuronium bromide $(0.1 \mathrm{mg} / \mathrm{kg}, \mathrm{IV})$. The day after surgery, a post-operative assessment was done to assess adverse effects such as hoarseness, sore throat, and unpleasant memories.

Based on a previous study by Gupta et al. [6], the required sample size was calculated to be 40 patients (randomly divided into two groups) to demonstrate a $40 \%$ difference in intubation time with a power of 0.8 and type 1 error of 0.05 . To allow for study error and attrition, a total of 60 patients were included in this study. Statistical analyses included using Student's $t$ test for parametric data, the Mann-Whitney $U$ test for non-parametric data, and Fisher's test for categorical data. The normality of the data was checked using the Shapiro-Wilk test. Continuous variables are expressed as mean (SD), and categorical variables as proportions (\%). $\mathrm{P}$ values $<0.05$ were considered to be statistically significant. The statistical evaluation was done using SPSS software (ver. 20.0; IBM Corp., USA).

\section{Results}

Demographic data were similar between the two groups. There was no significant difference between the groups in age, sex, body weight, or ASA physical status. The groups were also comparable in terms of airway difficulty, as assessed by modified Mallampatti grade, thyromental distance, and the upper lip bite test (Table 2).

All patients in both groups were intubated successfully. The mean intubation time for Group B [115.2 (14.7) s] was shorter than that for Group N [214.0 (22.2) s] (P = 0.029) (Fig. 2). The intubating conditions for Group B were better than those for Group N (P = 0.001). Twenty-four patients in Group B had optimal intubating conditions compared with only three in Group N. Vocal cord position was also more optimal for intubation in

Table 1. Grading System Used to Assess Intubating Conditions, Vocal Cord Position, and Patient Comfort and Satisfaction

\begin{tabular}{|c|c|c|c|c|c|c|}
\hline & \multirow[b]{2}{*}{ Intubating conditions } & \multirow{2}{*}{$\begin{array}{l}\text { Vocal cord } \\
\text { position }\end{array}$} & \multicolumn{3}{|c|}{ Patient comfort indices } & \multirow{2}{*}{$\begin{array}{c}\text { Post-operative } \\
\text { patient satisfaction }\end{array}$} \\
\hline & & & $\begin{array}{l}\text { Cough } \\
\text { severity }\end{array}$ & $\begin{array}{l}\text { Comfort during } \\
\text { intubation }\end{array}$ & $\begin{array}{l}\text { Post-intubation } \\
\text { assessment }\end{array}$ & \\
\hline Grade 1 & $\begin{array}{l}\text { Optimal } \\
\text { (no hold-up or collision of } \\
\text { tracheal tube with vocal cords) }\end{array}$ & $\begin{array}{l}\text { Relaxed/ } \\
\text { glottis open }\end{array}$ & No cough & No reaction & Cooperative & Excellent \\
\hline Grade 2 & $\begin{array}{l}\text { Suboptimal } \\
\text { (hold-up relieved by } \\
\text { one rotation of the tube) }\end{array}$ & $\begin{array}{l}\text { Moving/ } \\
\text { glottis partially open }\end{array}$ & $\begin{array}{l}\text { Slight } \\
\text { ( } \leq 2 \text { coughs })\end{array}$ & Grimacing & $\begin{array}{l}\text { Restless/minimal } \\
\text { resistance }\end{array}$ & Good \\
\hline Grade 3 & $\begin{array}{l}\text { Difficult } \\
\text { (hold-up requiring more than } \\
\text { one rotation of the tube) }\end{array}$ & $\begin{array}{l}\text { Adducted/ } \\
\text { glottis closed }\end{array}$ & $\begin{array}{l}\text { Moderate } \\
(3-5 \text { coughs })\end{array}$ & $\begin{array}{l}\text { Verbal } \\
\text { objection }\end{array}$ & $\begin{array}{l}\text { Severe resistance/ } \\
\text { requirement for } \\
\text { immediate general } \\
\text { anesthesia }\end{array}$ & Fair \\
\hline Grade 4 & $\begin{array}{l}\text { Failure } \\
\text { (failed attempt at awake } \\
\text { fiberoptic intubation) }\end{array}$ & - & $\begin{array}{l}\text { Severe } \\
(>5 \text { coughs })\end{array}$ & $\begin{array}{l}\text { Defensive } \\
\text { movements }\end{array}$ & - & Poor \\
\hline
\end{tabular}


Table 2. Demographic Data, Airway Assessment, and Intubation Time by Study Group

\begin{tabular}{lccc}
\hline & Group N & Group B & P value \\
\hline Age $(\mathrm{yr})$ & $44(10)$ & $44(10)$ & 0.732 \\
Sex $(\mathrm{M} / \mathrm{F})$ & $15 / 15$ & $17 / 13$ & 0.604 \\
Weight $(\mathrm{kg})$ & $64.7(8.1)$ & $65.9(11.3)$ & 0.657 \\
ASA physical status $(1 / 2)$ & $27 / 3$ & $25 / 5$ & 0.366 \\
Modified Mallampatti grade $(1 / 2 / 3 / 4)$ & $3 / 21 / 5 / 1$ & 0.264 \\
Thyromental distance $(\mathrm{cm})(>6.5 / 6-6.5 /<6)$ & $24 / 6 / 0$ & $2 / 18 / 8 / 2$ & 0.862 \\
Upper lip bite test $(1 / 2 / 3)$ & $14 / 15 / 1$ & $8 / 20 / 2$ & 0.131 \\
Intubation time $(\mathrm{s})$ & $214.0(22.2)$ & $115.2(14.7)$ & 0.028 \\
\hline
\end{tabular}

Data are presented as mean (SD) or number. ASA: American Society of Anesthesiologists.

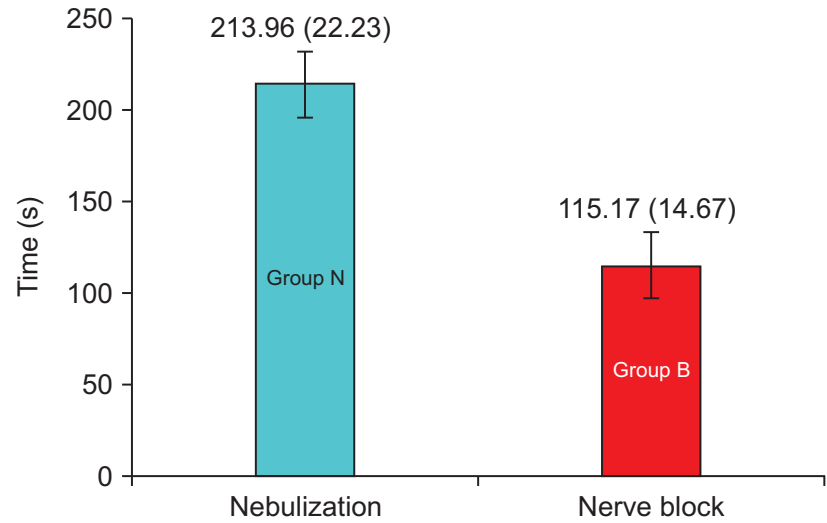

Fig. 2. Mean intubation time. Data are presented as mean (SD).

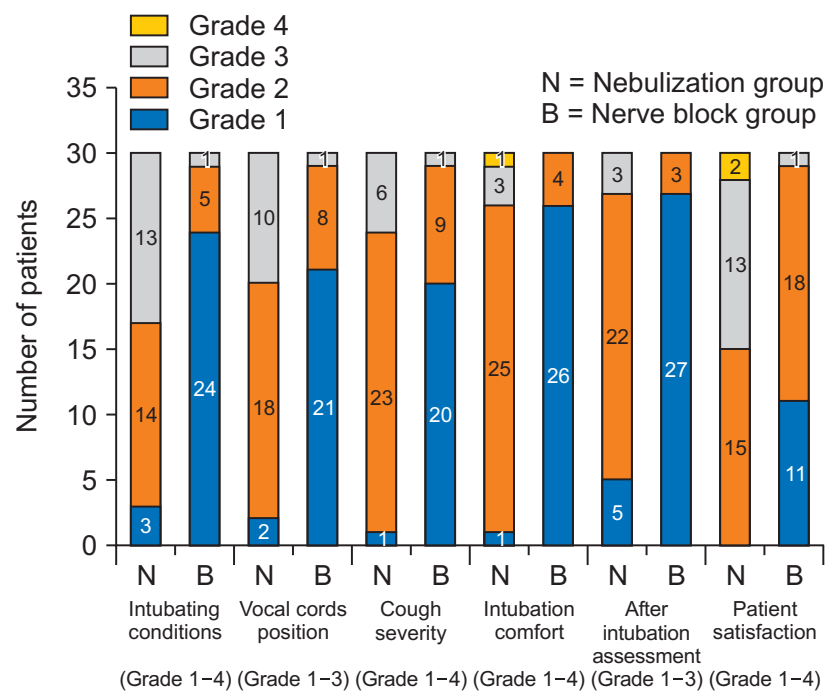

Fig. 3. Comparison of intubating conditions between two groups. Data are presented as the number of patients.

Group B compared with Group N (P = 0.002). Patient comfort during intubation, as assessed by cough severity $(\mathrm{P}=0.001)$ and intubation comfort scores $(\mathrm{P}=0.012)$, was higher in Group B than in Group N. Similarly, patient tolerability of endotracheal

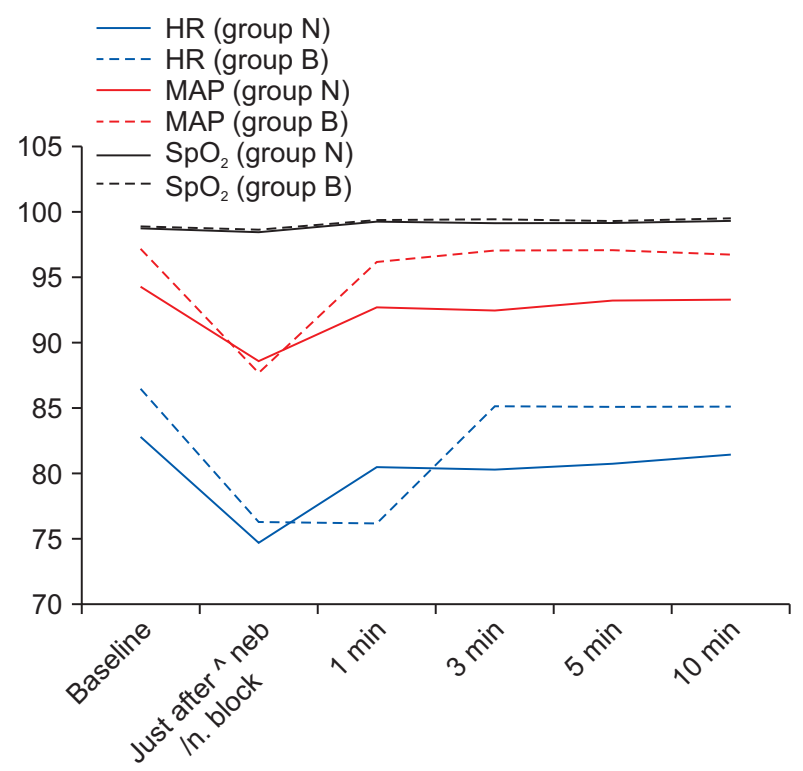

Fig. 4. Comparison of hemodynamic parameters between nebulization and nerve block groups. HR: heart rate, MAP: mean arterial pressures, $\mathrm{SpO}_{2}$ : oxygen saturation, $\wedge$ neb/n. block: nebulization/nerve blocks.

intubation, assessed post-intubation, was significantly higher in Group B than in Group N (P = 0.001) (Fig. 3).

Intragroup comparison of baseline heart rate and mean arterial pressure, with readings obtained just after nebulization or nerve block and 1 minute after awake fiberoptic intubation, revealed a significant reduction in heart rate and blood pressure in both groups, which returned to near baseline levels in subsequent readings taken at 3,5 , and $10 \mathrm{~min}$ after intubation. Heart rate and mean arterial pressure were comparable between the groups (Fig. 4).

Post-operative patient satisfaction scores for Group B were higher than those for Group N. In Group B, 29 patients rated their experience of awake fiberoptic intubation as excellent or good and none rated it as poor; however, in Group N, two patients rated the experience as poor and none rated it as excellent. The incidence rates of adverse effects, such as postoperative sore 
throat, hoarseness, and unpleasant memories, did not differ significantly between the two groups.

\section{Discussion}

Innovations and developments in the field of anesthesia have resulted in remarkable improvements in various aspects of airway management. Since the invention of the flexible fiberoptic bronchoscope in 1966 by Dr. Shigeto Ikeda [7], and its subsequent use for endotracheal intubation by Dr. Peter Murphy in 1967 [8], regional anesthesia for the airway has not only rendered awake fiberoptic intubation comfortable and acceptable for patients, but has also afforded anesthesiologists better control over intubation conditions.

Several authors have compared different airway anesthesia techniques. In 1990, Webb et al. [9] compared trans-cricoid lignocaine injection with use of the spray-as-you-go technique for awake fiberoptic bronchoscopy in 70 adult patients. In 1992, Graham et al. [10] compared three different methods of providing airway anesthesia during fiberoptic bronchoscopy in 53 patients. In 2000, Kundra et al. [11] compared nebulized lignocaine $4 \%$ with combined regional nerve block for awake fiberoptic nasotracheal intubation in 48 adult patients.

Airway nerve blocks are considered a gold standard and include: glossopharyngeal nerve blocks, which anesthetize the oropharynx and block the gag reflex; bilateral superior laryngeal nerve blocks, which anesthetize the larynx above the level of the vocal cords and block glottic closure reflex; and transtracheal nerve blocks, which anesthetize the trachea and larynx below the level of the vocal cords and abolish the cough reflex. Airway nerve block provides rapid and deep anesthesia with only small doses of local anesthetic, but a thorough knowledge of regional anatomy, as well as operator skill and experience, are required for correct application. The procedure also involves a risk of accidental intravascular injection and nerve injury, and airway nerve block is not feasible when there is distorted anatomy, such as in cases of massive neck swelling, traumatic injury to the head and neck, and local infection [4,5]. Nebulization of local anesthetics is another technique that deposits fine droplets of local anesthetic directly over the mucosa, thus anesthetizing it and obviating the need for multiple painful injections. Furthermore, this technique requires less detailed knowledge of anatomy, less specialist skills, and less experience; it can also be used in cases of massive neck swelling where nerve block cannot be performed. However, it has some disadvantages including the requirement for large doses of local anesthetic (due to wastage during administration), a higher chance of failure, and a delayed onset of action.

In this study, we used $10 \mathrm{ml}$ of $4 \%$ lignocaine $(400 \mathrm{mg}$ ) for nebulization in adult patients, based on a previous study by
Sutherland et al. [12], who found that lignocaine nebulization using a median dose of $512 \mathrm{mg}$ caused toxicity at a plasma concentration above $5 \mu \mathrm{g} / \mathrm{ml}$ in two of their patients, but that a dose of $370 \mathrm{mg}$ did not lead to toxicity. Gjonaj et al. [13] compared 8 $\mathrm{mg} / \mathrm{kg}$ and $4 \mathrm{mg} / \mathrm{kg}$ lignocaine for nebulization and found both doses to be safe, while Parkes et al. [4], who used $6 \mathrm{mg} / \mathrm{kg}$ lignocaine, did not observe a maximum plasma lignocaine level exceeding $0.45 \mathrm{mg} / \mathrm{L}$ in any of their subjects. Because there was no way to measure plasma lignocaine concentrations in our study, we limited the maximum dose of lignocaine to $400 \mathrm{mg}$. A higher concentration of lignocaine would have reduced the total effective volume reaching the airway mucosa if the dose remained the same. Hence, we deemed it sufficient to use a maximum concentration of lignocaine of $4 \%$, in a possible volume of $10 \mathrm{ml}$, to produce effective anesthesia without causing lignocaine toxicity.

In our study, there was no failure of intubation in either group. The mean intubation time was significantly shorter in the nerve block group; this was similar to the findings of Gupta et al. [6], who reported a mean intubation time of 123 (46.7) s in a nerve block group and 200.4 (72.4) s in a nebulization group $(\mathrm{P}=0.047)$. However, Reasoner et al. [14] found no significant difference in intubation time between nerve block and topical anesthesia groups, and in both of their groups, the intubation time was longer than in any other study. In contrast to our study, the degree of operator skill with awake fiberoptic intubation was not specified in any previous report.

In our study, the intubating conditions were better in Group B compared with Group N, similar to the studies of Webb et al. [9], Graham et al. [10], and Sethi et al. [15]. However, Reasoner et al. [14] and Gupta et al. [6] found no significant difference in intubating conditions between groups. It should be noted that no standardized scale for evaluating intubating conditions was used in previous studies, so we could not directly compare their intubating conditions with those of our study.

We compared patient comfort between our two study groups according to cough severity and intubation comfort scores during and after intubation; patient comfort was higher in the nerve block group. This can be attributed to the deposition of local anesthetic in the vicinity of the nerves. However, during nebulization, the local anesthetic is deposited over the mucosa, i.e., away from the nerves, so a larger amount of local anesthetic is needed. Furthermore, unpredictable deposition amounts due to wastage can lead to patchy, less effective anesthesia. Gupta et al. [6] also observed significant coughing in their nebulization group compared with a nerve block group.

Reasoner et al. [14] and Gupta et al. [6], who used fentanyl for procedural sedation, also found no significant difference in hemodynamic parameters between their study groups. However, increased mean arterial pressure and heart rate relative to baseline were observed in the latter study, probably due to 
sympathetic stimulation during intubation. In contrast, hemodynamic parameters remained stable in our patients and there was no sympathetic stimulation during intubation due to use of dexmedetomidine infusion for sedation. Although we noted a significant reduction in mean heart rate and blood pressure from baseline just after intubation in both groups, no patient required any pharmacological intervention and decreases in blood pressure and heart rate normalized within 3-5 minutes after fiberoptic intubation.

Contrary to our study, Kundra et al. [11] reported a progressive increase in heart rate in all of their patients, although the increase was significantly greater in the nebulization group than in the combined regional block group. The mean arterial pressure of their nebulization group was also higher than that of the combined regional block group. In our study, dexmedetomidine $(1 \mu \mathrm{g} / \mathrm{kg}, \mathrm{IV})$ before the procedure was effective in producing good sedation and analgesia, without marked alteration of hemodynamic parameters.

We found that oxygen saturation was comparable between Group N and Group B. The lowest recorded peripheral capillary oxygen saturation value was 95\%, in a patient from Group N. All patients received supplemental oxygen through the working channel of the bronchoscope, and no patient underwent desaturation during the fiberoptic bronchoscopy and subsequent intubation. The use of conscious sedation by dexmedetomidine infusion helped maintain sufficient sedation and patient cooper- ation during the procedure, and also preserved their respiration and prevented desaturation and hypoxia; thus, dexmedetomidine can be used safely instead of opioids such as fentanyl, as applied by Dhasmana [5] and Mondal et al. [16].

In our study, patient satisfaction scores recorded 24 hours after surgery were higher in Group B than in Group N. Adverse effects, such as sore throat, hoarseness, and unpleasant memories were not found to differ significantly between the groups. No other adverse effects, like hypoxia, severe hypotension, severe bradycardia, bradyarrhythmia, bronchospasm, or seizures due to lignocaine toxicity were recorded in either group.

Our study included patients with all grades of airway, so the results cannot be directly extrapolated to cases with difficult airways, in which fiberoptic intubation is most often used; thus, further studies are required. We could not measure the plasma lignocaine levels of our patients due to the non-availability of this facility at our institution.

In conclusion, this study revealed that airway anesthesia using airway nerve blocks is superior to lignocaine nebulization for awake fiberoptic bronchoscopy-guided nasotracheal intubation, in terms of ease of intubation and patient comfort and satisfaction. Nevertheless, lignocaine nebulization may be used as an alternative technique for airway anesthesia when a nerve block is not feasible because we observed no case of failure of awake fiberoptic intubation and no complications related to nebulization.

\section{References}

1. Panchabhai TS, Mehta AC. Historical perspectives of bronchoscopy. Connecting the dots. Ann Am Thorac Soc 2015; 12: 631-41.

2. Yrigoyen E, Fujikawa YF. Flexible fiberoptic bronchoscopy. Anesthesia, technique and results. West J Med 1975; 122: 117-22.

3. Díaz-Jimenez JP, Rodriguez AN. Interventions in Pulmonary Medicine. Houston, Springer. 2013, pp 13-31.

4. Parkes SB, Butler CS, Muller R. Plasma lignocaine concentration following nebulization for awake intubation. Anaesth Intensive Care 1997; 25: 369-71.

5. Dhasmana SC. Nasotracheal fiberoptic intubation: patient comfort, intubating conditions and hemodynamic stability during conscious sedation with different doses of dexmedetomidine. J Maxillofac Oral Surg 2014; 13: 53-8.

6. Gupta B, Kohli S, Farooque K, Jalwal G, Gupta D, Sinha S, et al. Topical airway anesthesia for awake fiberoptic intubation: comparison between airway nerve blocks and nebulized lignocaine by ultrasonic nebulizer. Saudi J Anaesth 2014; 8(Suppl 1): S15-9.

7. Ikeda S, Yanai N, Ishikawa S. Flexible bronchofiberscope. Keio J Med 1968; 17: 1-16.

8. Murphy P. A fibre-optic endoscope used for nasal intubation. Anaesthesia 1967; 22: 489-91.

9. Webb AR, Fernando SS, Dalton HR, Arrowsmith JE, Woodhead MA, Cummin AR. Local anaesthesia for fibreoptic bronchoscopy: transcricoid injection or the "spray as you go" technique? Thorax 1990; 45: 474-7.

10. Graham DR, Hay JG, Clague J, Nisar M, Earis JE. Comparison of three different methods used to achieve local anesthesia for fiberoptic bronchoscopy. Chest 1992; 102: 704-7.

11. Kundra P, Kutralam S, Ravishankar M. Local anaesthesia for awake fibreoptic nasotracheal intubation. Acta Anaesthesiol Scand 2000; 44: 511-6.

12. Sutherland AD, Santamaria JD, Nana A. Patient comfort and plasma lignocaine concentrations during fibreoptic bronchoscopy. Anaesth Intensive Care 1985; 13: 370-4.

13. Gjonaj ST, Lowenthal DB, Dozor AJ. Nebulized lidocaine administered to infants and children undergoing flexible bronchoscopy. Chest 1997; 112: 1665-9.

14. Reasoner DK, Warner DS, Todd MM, Hunt SW, Kirchner J. A comparison of anesthetic techniques for awake intubation in neurosurgical 
patients. J Neurosurg Anesthesiol 1995; 7: 94-9.

15. Sethi N, Tarneja VK, Madhusudanan TP, Shouche S. Local anaesthesia for fiberoptic intubation: a comparison of three techniques. Med J Armed Forces India 2005; 61:22-5.

16. Mondal S, Ghosh S, Bhattacharya S, Choudhury B, Mallick S, Prasad A. Comparison between dexmedetomidine and fentanyl on intubation conditions during awake fiberoptic bronchoscopy: a randomized double-blind prospective study. J Anaesthesiol Clin Pharmacol 2015; 31: 212-6. 